\title{
Turismo rural na agricultura familiar - TRAF: oportunidades e desafios em relação às especificidades do setor de serviços
}

\author{
Ronie Peterson SILVESTRE ${ }^{1^{*}}$ \\ ${ }^{1}$ Departamento de Administração, Universidade Federal de Rondônia, Vilhena, RO, Brasil \\ *E-mail: ronie@unir.br
}

Recebido em maio/2018; Aceito em julho/2018.

RESUMO: Este artigo procura refletir sobre as oportunidades e os desafios que emergem ao agricultor familiar em decorrência das especificidades da administração de serviços presentes na criação e no desenvolvimento de atividades turísticas em suas propriedades rurais. O método de pesquisa é bibliográfico e como resultados o autor propõe um diagrama que procura demonstrar a simultaneidade entre as atividades agropecuárias tradicionais (produção de bens) e as atividades relacionadas ao turismo rural (oferta de serviços) e alguns possíveis desdobramentos que poderão surgir da interdependência desses dois sistemas sob a luz das particularidades da agricultura familiar e do Turismo Rural na Agricultura Familiar - TRAF.

Palavras-chave: atividades agropecuárias, extensão rural, pluriatividade.

\section{Rural tourism in family farming - TRAF: opportunities and challenges in relation to the specificities of the services sector}

\begin{abstract}
This article seeks to reflect on the opportunities and challenges that emerge for the family farmer due to the specifics of the administration of services present in the creation and development of tourist activities in their rural properties. The research method is bibliographical and as results the author proposes a diagram that tries to demonstrate the simultaneity between the traditional agricultural activities (production of goods) and the activities related to the rural tourism (service offer) and some possible consequences that may arise from the interdependence of these two systems, in light of the particularities of Family Agriculture and Rural Tourism in Family Agriculture - TRAF.

Keywords: agricultural activities, rural extension, pluriactivity.
\end{abstract}

\section{INTRODUÇÃO}

A agricultura familiar historicamente sofreu inúmeras transformações tanto de ordem econômica, como o aparecimento do modo capitalista de produção (mercantilização), como de ordem política traduzidas por imposições quanto ao modo que esses agricultores deveriam estar organizados (BAIARDI, 2014). Essas mudanças poderiam ter aniquilado a agricultura familiar, no entanto, segundo a autora, a sobrevivência desse modo de vida e de produção demonstraram ao longo do tempo a forte capacidade de resiliência dos agricultores familiares. Contemporaneamente, a agricultura familiar e a própria noção a respeito do rural se apresentam em configurações bastante variadas, multifacetadas. O meio rural está mais conectado ao sistema urbano e experimentam trocas materiais e imateriais constantes numa situação de interdependência. As atividades desenvolvidas nas propriedades e as fontes de renda passam a não depender exclusivamente da agropecuária, pelo contrário, em muitas unidades as atividades não-agrícolas às superam. Esse fenômeno vem sendo discutido e analisado por diversos estudiosos com a denominação de pluriatividade.

A pluriatividade é a estratégia das famílias rurais como resposta às pressões externas suscitadas a partir de agentes econômicos mais poderosos, a mercantilização (NIEDERLE; SCHNEIDER, 2007). A capacidade de maleabilidade da agricultura familiar permite que ela se organize e reorganize lançando mão de estratégias emergentes e deliberadas relacionadas à própria agricultura e também buscando fontes de renda fora dela, de forma que a unidade produtiva e as características próprias da família agricultora sobrevivam. De fato, sem a estratégia da pluriatividade as unidades familiares estariam sempre reféns à apropriação externa, como bem definiu Abramovay (1992) que "um cínico poderia dizer que a unidade familiar é uma instituição que funciona para estimular as unidades familiares a ofertar parcelas de trabalho e de capital a taxas de retorno abaixo do normal de maneira a oferecer para a economia global produtos agrícolas a preços de barganha".

A partir da própria agricultura e das características da família agricultora, tem sido possível desenvolver estratégias não-agrícolas, como é o caso do turismo. Diversas unidades familiares têm complementado seus rendimentos por meio da atividade. O que chama a atenção para esse trabalho é que a implantação de ofertas turísticas no meio rural insere concepções bem diferentes a que o agricultor familiar estava ambientado, a começar pelos fatores preponderantemente intangíveis que o turismo produz e opera. Além de um arcabouço de conceitos e teorias diferentes daquelas aplicadas aos demais setores que produzem bens, o agricultor precisa "enxergar" o não visível em suas rotinas e produtos finais, que são em sua essência concretos. Esse exercício pode não ser tão fácil, uma vez que o agricultor deverá perceber valor e significado em atividades e até mesmo em artefatos que historicamente eram desprovidos de algum tipo de valor econômico.

O objetivo desse trabalho é refletir sobre as oportunidades e os desafios que emergem ao agricultor familiar em 
decorrência das especificidades da administração de serviços presentes na criação e no desenvolvimento de atividades turísticas em suas propriedades rurais. Para tanto, há que se refletir sobre a agricultura familiar contemporânea, sobre a concepção do valor turístico e das especificidades da oferta de serviços. Definida a problemática, realizou-se a pesquisa bibliográfica sobre o Turismo Rural na Agricultura Familiar, conceitos de percepção de valor, de valor intangível e das singularidades relacionadas ao setor de prestação de serviços. Ao final o autor propõe um diagrama na tentativa de demonstrar como os processos e resultados da agricultura tradicional podem gerar outros valores econômicos à partir da inserção de aspectos intangíveis e discute alguns desafios decorrentes da inserção de novos conhecimentos e atitudes relacionadas à administração de serviços.

\section{REVISÃO DE LITERATURA}

\subsection{Turismo: uma economia de peculiaridades.}

As teorias formuladas pelos economistas ao longo dos tempos vieram tecendo conceitos que podem contribuir para o desenvolvimento da atividade, pois acredita-se que o valor do produto turístico não é passível de ser precificado apenas através dos custos fixos e variáveis, mas sim, principalmente, por meio do valor que as pessoas atribuem, sentem, percebem sobre o que se oferta (McINTOSH, 2002; RUSCHMANN, 1990).

David Ricardo desenvolveu a ideia de que os produtos podem ser reproduzíveis e consequentemente apresentar as propriedades de ser útil e de possuir valor. Marx diverge os conceitos formulados pelos clássicos Smith e Ricardo e afirma que o valor é oriundo da exploração do capital sobre os trabalhadores, a mais-valia. "O valor de uma mercadoria é o trabalho abstrato direto e indireto socialmente necessário à produção dessa mercadoria" (SALAMA; VALIER, 1975). Para os economistas neoclássicos, o valor é formado pela utilidade marginal que determinado bem tem para um indivíduo de acordo com suas necessidades. Essa linha de pensamento é que idealizou o conceito de soberania do consumidor. Lemos (2005) busca em León Walras uma definição de riqueza social sendo como "o conjunto de todas as coisas, materiais e imateriais, que são suscetíveis de ter um preço porque são escassas, isto é, por um lado são úteis e, por outro, só estão disponíveis em quantidades limitadas". John Maynard Keynes retoma a ideia de equilíbrio econômico combatendo o conceito, principalmente após a crise de 1929. "O volume de emprego de uma economia depende da demanda efetiva, ou seja, da proporção de renda que é gasta em investimento. Demonstrou também que deveria haver um agente responsável pelas políticas econômicas compensatórias, o governo" (LEMOS, 2005).

As contribuições dessas teorias para as atividades turísticas são bem mais detalhadas na obra de Lemos (2005) que pode ser referência para estudos da área. A ideia central que é extraída da obra, é que nenhuma teoria já elaborada pode explicar, isoladamente, o valor econômico do turismo de forma satisfatória pois "trata-se de um processo que tem por base as próprias relações sociais e as diversas formas de produção humana, não só as mercantis" (LEMOS, 2005).

As relações sociais, a cultura, o clima, a flora e a fauna, o patrimônio histórico, os potenciais hídricos, a gastronomia entre outros, quando compreendidos como valor turísticos poderão receber tratamento e interpretações mais adequadas.
Nesse sentido, também fica evidente que transformar relações sociais e recursos endógenos em produtos turísticos requer capacidade criativa. A cultura, o capital intelectual e o patrimônio histórico quando desenvolvidos e ofertados ao mercado tem sido conhecido como Economia Criativa (MIGUEZ, 2007). Diversos países têm buscado fomentar esse tipo de economia pois sua fonte de vantagem competitiva é mais sustentável, uma vez que explora recursos e capacidades únicas de valores intangíveis e difíceis de se imitar (REIS, 2008; BARNEY, 2007).

\subsection{Turismo Rural na Agricultura Familiar - TRAF}

O agricultor familiar é aquele que possui área relativamente pequena ou média, que administra e trabalha com sua família nessa unidade produtiva e que não possui trabalhadores contratados em número acima dos membros de sua família (GUANZIROLI; CARDIM, 2000). Para gerar resultados positivos sobre os investimentos e o trabalho aplicado às atividades agropecuárias tradicionais, o agricultor familiar precisa tomar decisões em um ambiente interno repleto de singularidades como a sazonalidade da produção, a influência de fatores biológicos e edafoclimáticos e, entre outros, a rápida perecibilidade dos produtos (AZEVEDO, 2001; ARAÚJO, 2008). Ao participar do mercado, o agricultor familiar é considerado o agente mais suscetível da cadeia de valor pois sofre a desvalorização de seus produtos agrícolas por conta de um ambiente com forte estrutura de oligopólio e oligopsônio (ARAÚJO, 2008). Normalmente, para ter acesso aos mercados ele comercializa seus produtos por meio de intermediários, e se optarem pela produção de commodities, terão ainda menos controle sobre os preços a serem comercializados.

Portanto, os produtos comercializados pela agricultura tradicional, são normalmente, produtos com pouca agregação de valor, e durante a produção dos mesmos o agricultor é o elo da cadeia produtiva que está mais sujeito à variáveis incontroláveis do ambiente interno, e os que mais assumem riscos sobre as consequências negativas geradas pelo ambiente externo ou pela mercantilização (SCHNEIDER, 2003). Face a sua resiliência histórica, a agricultura familiar tem buscado estratégias alternativas, e na maioria das vezes emergentes a fim de obter rendimentos fora das atividades agrícolas, mas ao mesmo tempo sem abandoná-las (BAIARDI, 2014). O turismo tem sido uma dessas estratégias alternativas relacionadas às multifunções que a agricultura dispõe, ainda que a atividade imponha ao agricultor outros desafios relacionados às especificidades do setor de serviços. Segundo E. Santo (2002), "não há motivo para negar as multifunções da agricultura, por exemplo, a preservação do meio ambiente e a biodiversidade. Também compreensível estender um pouco mais a concepção e abranger também a questão da paisagem rural e do agroturismo".

Entretanto, para a maioria dos estudiosos, o Turismo rural precisa ser melhor compreendido quanto à conceituação e terminologias. Para Tulik (2003), a dificuldade na definição de um conceito reside na ambiguidade do termo e dos critérios utilizados para delimitar espaços rurais e urbanos. Para dirimir as "confusões terminológicas" entre os diversos termos já criados como ecoturismo, turismo ecológico, agroturismo etc., a autora sugere o termo "turismo no meio rural". Outros, como Rodrigues (2000) e Graziano (2000) utilizam a expressão "Turismo no espaço rural". Esse termo 
genérico se deve às inúmeras possibilidades e complexidades de produtos turísticos em relação a exploração do turismo nas propriedades rurais. (ALMEIDA; BLOSS, 2000).

Em Candiotto (2010), o autor se dedica a debater sobre essas e outras terminologias acerca da atividade. Para os objetivos desse texto utilizaremos o termo "Turismo Rural na Agricultura Familiar - TRAF" que possui conceito construído especificamente para tratar da atividade na agricultura familiar, sendo:

A atividade turística que ocorre na unidade de produção dos agricultores familiares que mantêm as atividades econômicas típicas da agricultura familiar, dispostos a valorizar, respeitar e compartilhar seu modo de vida, o patrimônio cultural e natural, ofertando produtos e serviços de qualidade e proporcionando bem-estar aos envolvidos (BRASIL/PNTRAF, 2004).

Esse conceito tem maior relação com o que Ruschmann (2000) chamou de "forma mais original e pura". Para a autora "[...] O turismo rural deve estar constituído em estruturas eminentemente rurais, de pequena escala, ao ar livre, proporcionando ao visitante o contato com a natureza, com a herança cultural das comunidades do campo e as chamadas sociedades e práticas 'tradicionais"'. Ruschmann (1997) e Swarbrooke (2000), defendem ainda que o turismo deve estar alicerçado sob os preceitos da sustentabilidade, pois é a base de sua valoração, sem a qual, o pensamento apenas mercantil levaria as unidades a desconstrução.

Para Zimmermann (2000), uma das características principais do turismo rural consiste em fomentar o atendimento familiar e a cultura local. Segundo o autor, a atividade turística não pode estar alheia às demais atividades tradicionais do campo. Dessa forma, o TRAF procura valorizar os diferenciais promovidos pelas idiossincrasias da agricultura familiar em relação às propriedades patronais e aos neo-rurais (BRASIL, 2004; CANDIOTTO, 2013; RAMIRO, 2015). Ainda assim, percebe-se que são extensas as possibilidades de criação de produtos turísticos pelos agricultores familiares. O Programa Nacional de Turismo Rural para a Agricultura Familiar (PNTRAF) relaciona as seguintes ofertas:

Produção e comercialização de artesanato

Produção e comercialização de produtos agropecuários Hospedagem

Participação nos processos de produção em locais como pomares, leiterias, apiários, criações de animais em geral, áreas cultivadas, vinícolas, alambiques.

Pesca e pesque-pague

Banhos em rios, lagos, represas, cachoeiras Atividades lúdicas em geral

Cavalgadas

Passeios de barco

Figura 1. Possibilidades de criação de produtos turísticos pelos agricultores familiares. Fonte: Adaptado de Brasil/PNTRAF (2004).

Figure 1. Possibilities for the creation of tourist products by family farmers. Source: Adapted from Brasil/PNTRAF (2004).

O Turismo rural também tem sido apontado como um importante meio para o desenvolvimento local e regional, como a melhoria das condições de vida das famílias rurais, a diminuição do êxodo rural e o resgate da auto-estima do agricultor (EMBRATUR, 2004). Ruschmann (2000), chegou a classificar o Turismo rural como uma "locomotiva" do desenvolvimento rural e tem contribuído para o desenvolvimento socioeconômico de vários municípios no Brasil e também de outros países (ZIMMERMANN, 2000; GRAZIANO, 2000; PRESVELOU, 2000).

No entanto, nos últimos anos alguns pesquisadores têm buscado saber se o turismo rural realmente tem promovido esses e outros benefícios. Soares (2007) aponta nos resultados de sua tese que para algumas localidades a implantação do turismo em nada ajudou os agricultores, e Froehlich (2000) também questiona se as vantagens prometidas pela atividade não estariam beneficiando apenas os agricultores familiares consolidados. "Frente às condições sociais e econômicas tão precárias apresentadas, pode mesmo o turismo rural ser uma estratégia de inclusão dos excluídos ou semi-excluídos, como os agricultores 'periféricos' ou 'de transição', no processo de desenvolvimento?" (FROEHLICH, 2000). E Candiotto (2013) alerta sobre a subordinação do agricultor familiar ao trade turístico e sua consequente perda de autonomia. Os trabalhos mais recentes sobre o tema são cautelosos em atribuir apenas vantagens à prática do Turismo
Antiguidades, inclusive maquinário e instrumentos agrícolas e do lar Arquitetura (casas, galpões, moinhos, armazéns, adegas, pontes),

Atendimento tipicamente familiar

Rusticidade característica do meio

Manifestações folclóricas, causos, lendas, músicas Educação ambiental Atrativos culturais, naturais, tecnológicos nas comunidades ou propriedades próximas, a exemplo de festas populares e religiosas,

Caminhadas

rural e parece haver um entendimento de que a atividade não é uma solução para todo e qualquer tipo de problema enfrentado pelas unidades familiares (CANDIOTTO, 2013; RAMIRO, 2015).

\subsection{Serviços, Intangibilidade e Turismo rural}

São inúmeras as oportunidades de gerar valor a partir do conceito da intangibilidade, entretanto o conceito gera muitos desafios, pois a intangibilidade dos serviços "são desempenhos, ações e esforços, como resultado, eles não podem ser vistos, sentidos, degustados da mesma forma que os bens tangíveis" (HOFFMAN, 2003).

Kotler (2000) define serviço como, "qualquer ato ou desempenho que uma parte possa oferecer a outra e que seja essencialmente intangível e não resulte na propriedade de nada". Sua produção pode ou não estar vinculada a um produto físico". Para Drucker (2002) "O cliente nunca compra determinado produto. Por definição, compra a satisfação de um desejo. Compra valor". A prestação de serviços turísticos segue a mesma essência pois "o produto turístico difere, fundamentalmente, dos produtos industrializados e de comércio. Compõe-se de elementos e percepções intangíveis e é sentido pelo consumidor como uma experiência" (RUSCHMANN, 1990). Na Figura 2, Grönroos (1993) estabelece as principais diferenças entre a oferta de produtos físicos e a oferta de serviços. 
Depois da intangibilidade, os conceitos de inseparabilidade, heterogeneidade e perecibilidade são as características da administração de serviços que mais impactam diretamente na relação entre organização e clientes.

\begin{tabular}{|l|l|}
\hline Bens físicos & Serviços \\
\hline Tangível & Intangível \\
Homogêneo e distribuição & Heterogêneo \\
Produção e duçã distribuição e \\
separadas do consumo \\
consumo são processos \\
simultâneos.
\end{tabular}

Figura 2. Diferenças entre serviços e bens físicos. Fonte: Grönroos (1993).

Figure 2. Differences between services and physical goods. Source: Grönroos (1993).

\subsubsection{Inseparabilidade}

$\mathrm{Na}$ produção de bens predominantemente tangíveis, o cliente não conhece onde e como ele é produzido. Ou seja, o cliente está separado da produção, enquanto em serviços a "produção" é concebida sob os olhos dos clientes (GRÖNROOS, 1993). Essa característica exige treinamento adequado aos colaboradores e, dentre outras, com a higiene, limpeza e organização do local. Atentando para todos os aspectos que geram impressões positivas aos usuários, pois a experiência dos clientes é simultânea à produção dos serviços. A inseparabilidade também faz com que clientes interajam com outros clientes no ambiente onde está sendo oferecido o serviço, esta característica pode, às vezes, trazer bons resultados e, outras vezes, problemas de difícil resolução (HOFFMAN, 2003).

\subsubsection{Heterogeneidade}

A heterogeneidade se refere a impossibilidade de padronização na prestação dos serviços. Devido a inseparabilidade, não há como preparar o produto antes do cliente. $\mathrm{O}$ cliente e o provedor de serviços agem no mesmo momento e esse produto pode sofrer várias influências enquanto é "consumido" (GRÖNROOS, 1993). A qualidade da oferta depende do estado emocional do funcionário, da disponibilidade dos insumos ou até mesmo da personalidade do cliente. Os encontros são singulares e por isso a dificuldade de padronização e excelência na qualidade (HOFFMAN, 2003).

\subsubsection{Perecibilidade ou não-estocável}

"Ao contrário dos bens, que podem ser armazenados e vendidos depois, os serviços que não são vendidos quando disponíveis cessam de existir" (HOFFMAN, 2003). Esta quarta característica também é consequência da intangibilidade e deve ser tratada com perspicácia e criatividade, pois pela impossibilidade de se estocar produtos intangíveis, fica igualmente difícil equilibrar a capacidade da oferta com a demanda. Existem ações interessantes que podem ser encontradas em obras bibliográficas sobre Administração de Serviços que têm sido praticadas com o intuito de amenizar os impactos negativos dessa e das demais características.

Essas características também influenciam diretamente na maneira de se elaborar estratégias mercadológicas para o setor de serviços. Enquanto o clássico composto de marketing (produto, preço, praça e promoção) é amplamente utilizado para desenvolver as ofertas de bens, para o setor de serviços foi necessário adicionar à ferramenta outros elementos que pudessem abranger adequadamente os objetivos do setor: pessoas, processos e physical evidence (BOOMS; GRÖROOS, 1993). Para os autores as pessoas são recursos essenciais a serem considerados uma vez que seus processos não se desenvolvem longe do cliente (inseparabilidade). Portanto o desenvolvimento e treinamento das pessoas para o atendimento ao público são cruciais a fim de minimizar o efeito da heterogeneidade dos serviços. A evidência física ou tangibilidade (ZEITHML et al., 2014) refere-se a qualidade dos aspectos físicos apresentados no ambiente que, em tese, estariam evidenciando boa qualidade na prestação dos serviços também. Zeithml et al. (2014) se dedicaram a estudar os serviços a partir de seus elementos de qualidade. Os autores classificaram essas variáveis em cinco dimensões: tangibilidade, confiabilidade, responsividade, garantia e empatia, conforme Figura 3.

\begin{tabular}{|l|l|}
\hline $\begin{array}{l}\text { Atributos de qualidade } \\
\text { em serviços }\end{array}$ & Descrição \\
\hline Tangibilidade & $\begin{array}{l}\text { Aspectos físicos do que é fornecido } \\
\text { aos usuários }\end{array}$ \\
\hline Confiabilidade & $\begin{array}{l}\text { Habilidade de cumprir o que foi } \\
\text { prometido com exatidão }\end{array}$ \\
\hline Responsividade & $\begin{array}{l}\text { Capacidade para atender os usuários e } \\
\text { fornecer o serviço prontamente, } \\
\text { capturando a noção de flexibilidade e } \\
\text { habilidade para adaptar o serviço às } \\
\text { necessidades do usuário. }\end{array}$ \\
\hline Garantia & $\begin{array}{l}\text { Competência e cortesia estendida aos } \\
\text { usuários e a segurança fornecida } \\
\text { através das operações }\end{array}$ \\
\hline Empatia & Atenção individualizada aos usuários \\
\hline
\end{tabular}

Figura 3. Os cinco atributos de qualidade na prestação de serviços. Fonte: Adaptado de Zeithml et al (2014).

Figure 3. The five attributes of quality in service delivery. Source: Adapted from Zeithml et al (2014).

Com exceção da tangibilidade, percebe-se que as demais dimensões dizem respeito a atuação das pessoas no momento da prestação dos serviços. Diversas organizações prestadoras de serviços em todo mundo têm sido pesquisadas a partir do Modelo criado por esses autores.

Com relação a prestação de serviços turísticos, McIntosh (2002) propuseram a adição de mais dois atributos ao composto de marketing de serviços. Para eles essas dimensões traduziam de forma mais apropriada os pontos críticos do turismo: programação e parcerias. As programações são consideradas por McIntosh (2002) sendo "atividades especiais, eventos ou outros tipos de programas para aumentar a despesa dos clientes ou acrescentar apelo a um pacote ou outro serviço turístico". As parcerias, são cooperações ou alianças entre os diversos agentes interessados com o objetivo de unir as competências 
distintivas de cada interessado (MCINTOSH, 2002; BARNEY, 2007). Além disso, Mill; Morrison substituem o conceito de place (praça) por acessos e facilidades, pois na atividade turística, a única forma de prestar os serviços é o cliente se deslocando até a localidade receptora (RUSCHMANN, 1990).

Existem outras consequências geradas pela intangibilidade que não são aqui aprofundadas como: a dificuldade do uso de patentes, dificuldade de percepção pelo cliente, dificuldade de comunicação, dificuldade para vender em mercados geograficamente distantes, entre outras (HOFFMAN, 2003). Apesar da complexidade citada para lidar com a prestação de serviços em comparação ao comércio e fabricação de bens, inúmeras organizações estão buscando oferecer mais serviços, o que reflete a visão de que os aspectos intangíveis dos produtos os diferenciam no mercado e os tornam mais competitivos (BARNEY, 2007). Para Kaplan; Norton (2004), "os ativos intangíveis são a fonte definitiva de criação de valor sustentável.

2.4. Reflexões sobre as oportunidade e desafios do TRAF sob a ótica dos serviços e da intangibilidade.

A Agricultura familiar pode transformar recursos que usualmente não são geradores de valor econômico a partir da compreensão dos significados que o campo e a natureza possuem na mente, principalmente, dos residentes urbanos. Esses significados valorizados pelo agricultor familiar e transformados em produtos turísticos podem dar início a um segmento com maior valor agregado em complemento às suas atividades agropecuárias normais.

A Figura 4 procura mostrar simultaneamente por meio de um diagrama, um fluxo simplificado das atividades agropecuárias tradicionais (áreas não hachuradas) e outro fluxo das atividades relacionadas ao TRAF (áreas hachuradas).

O objetivo do diagrama é propiciar uma visão mais sistêmica de como os processos e os produtos finais da agropecuária são acrescidos de maior oferta de serviços e de valor intangível por meio do TRAF. O Turismo rural oferece ao agricultor familiar inúmeras possibilidades de criação de valor por conta da maior liberdade na formulação de estratégias, diferentemente dos processos relacionados à produção agrícola. Em outras palavras, as incertezas maiormente presentes nas atividades agrícolas, poderão ser compensadas pela renda obtida por meio da prestação de serviços que são passíveis de maior controle, além de que, os serviços são frutos da criatividade enquanto as commodities e outros produtos agrícolas são mais suscetíveis às oscilações do mercado e dos fatores naturais, e, portanto, menos controláveis.

Os processos comuns ou tradicionais à produção agropecuária podem ser aproveitados e adaptados para as finalidades turísticas quando esses mesmos processos passam a ser vistos pelo próprio agricultor familiar não apenas como geradores de despesas, mas sim como detentores de significados socioculturais, históricos e ambientais. A partir dessa consciência, é possível que os recursos já existentes forneçam ao agricultor familiar a base para a configuração de ambientes e ofertas turísticas criativas.

Além disso, a produção gerada pela agropecuária pode ser comercializada no próprio local sem a dependência de intermediários e, consequentemente, podendo ajustar melhor seus preços de acordo com os custos decorridos da produção. Nota-se que nesse caso o agricultor passa a ser o agente detentor de informações e não os intermediários. Os excedentes ainda poderão ser vendidos via modelos tradicionais.

Outra observação importante é que as duas estruturas ou fluxos são interdependentes. Todas as ofertas criadas e outros elementos tangíveis e intangíveis relacionados ao turismo rural estão atrelados ao desenvolvimento da atividade agropecuária e ao modo de vida da família agricultora.

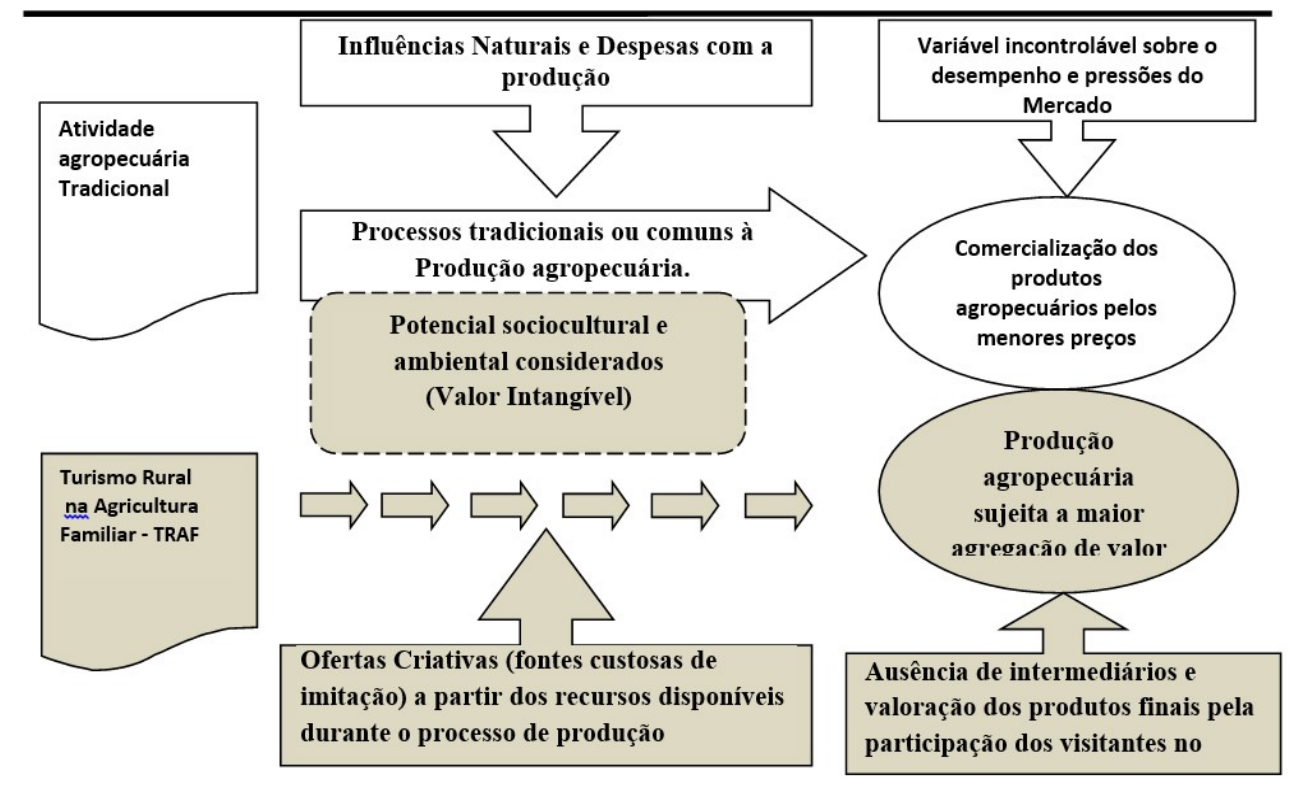

Figura 4. Simultaneidade entre os processos agropecuários tradicionais e o TRAF. Fonte: o autor.

Figure 4. Simultaneity between traditional agricultural processes and TRAF. Source: the author.

Por outro lado, quando essas duas estruturas se unem, as atividades tradicionais do meio agrícola e o modo como elas 
são executadas estão sujeitas à adequações uma vez que os turistas - quase sempre residentes urbanos e inclusive crianças - são inseridos ao mesmo ambiente e valorizam algumas características como segurança, disponibilidade das ofertas e responsividade por parte da família agricultora. Neste caso, o agricultor e sua família sofrem as implicações da inseparabilidade, pois os visitantes estarão presentes no ambiente produtivo (agropecuário) "consumindo" as ofertas, simultaneamente enquanto elas são produzidas pelos agricultores. Nesse sentido, fica notório o quão complexo se torna o ambiente interno e externo das unidades familiares a partir da junção dos dois segmentos, o agropecuário e o TRAF, e como se multiplicam os conhecimentos e habilidades necessárias ao agricultor familiar para operar nesses sistemas. De fato, se as atividades agropecuárias requerem deles conhecimentos sobre solo, adubação, irrigação, clima, ciclo biológico, equipamentos agrícolas, armazenamento, logística e etc., com a inserção do TRAF eles teriam que somar a esses, novos conhecimentos, habilidades e atitudes para satisfazer as diversas necessidades dos clientes que estarão em suas propriedades experimentando todos os elementos tangíveis e intangíveis existentes a sua volta.

\section{CONSIDERAÇÕES FINAIS}

A real compreensão sobre as particularidades do setor de serviços e do turismo rural pelos agricultores familiares é fundamental e deve favorecer a criação de produtos turísticos e a operacionalização dos processos de serviços. Esses novos conhecimentos deveriam abranger no mínimo três grandes áreas: serviços e seus conceitos elementares de intangibilidade, heterogeneidade, inseparabilidade e perecibilidade. Composto de marketing turístico contemplando as questões sobre pessoas, parcerias, programações e acessos e facilidades, além dos atributos de qualidade em serviços abordando a tangibilidade, confiança, responsividade, garantia e empatia.

Para tanto, esses e outros novos assuntos correlatos devem ser apresentados de forma adequada aos agricultores familiares, já que eles sempre estiveram ambientados a exercer suas funções tradicionais sem a presença de pessoas que estarão exigindo atenção e cuidados diversos. Nesse sentido, a extensão rural é do mesmo modo desafiada a incorporar, entre tantos outros conhecimentos importantes à agricultura familiar, os fundamentos do setor de serviços que são, em grande parte os conceitos básicos para a atividade turística. Não somente introduzir esses novos conhecimentos, mas estabelecê-los a partir de metodologias e de processos de ensino-aprendizagem que considere os princípios do TRAF acerca dos aspectos socioculturais, históricos, endógenos e econômicos. Esse entendimento corrobora com as pesquisas de Rameh (2011) e Ceretta (2013) que verificaram limitações dos agentes extensionistas para orientar e assessorar os agricultores familiares nos assuntos relacionados ao turismo rural. Esses desafios poderão ser acentuados quando se tratar da orientação e assessoria aos agricultores periféricos e em transição.

No demais, complementar a renda com o turismo não deve permitir a desagregação dos aspectos socioculturais, da sustentabilidade ambiental e das demais atividades tradicionais. Pelo contrário, o valor do turismo rural para a agricultura familiar está justamente nas peculiaridades relativas à vida $\mathrm{e}$ às atividades realizadas por eles. Agricultores familiares deveriam apropriar-se dos conhecimentos sobre administração e marketing de serviços de forma crítica e consciente. A aplicação dos conceitos e das ferramentas devem ocorrer de maneira autônoma e fundamentada sobre suas singularidades que, inclusive, os diferenciarão competitivamente das demais ofertas turísticas praticadas pelos neo-rurais. As Universidades poderiam cumprir um papel importante por meio da pesquisa, ensino e extensão em relação ao TRAF, podendo minimizar ou eliminar possíveis relações assimétricas entre os agricultores familiares e o trade turístico, e acima de tudo, valorizar a qualidade de vida dessas famílias. Como limitação da pesquisa, percebeu-se a necessidade de um maior aprofundamento sobre o setor de serviços, o que não seria possível neste artigo. Outras abordagens mais pontuais e aplicações de alguns instrumentos em pesquisas empíricas deverão ser realizadas.

\section{REFERÊNCIAS}

ABRAMOVAY, R. Paradigmas do capitalismo agrário em questão. 2. ed. Campinas SP: Editora da Unicamp, 1992. $396 \mathrm{p}$.

ALMEIDA, J. A.; BLOS, W. O marketing do turismo rural e o desenvolvimento sustentável. In: ALMEIDA, J. A.; FROEHLICH, J. M.; REIEDL, M. (Orgs). Turismo rural e desenvolvimento sustentável. 1. ed. Campinas: Papirus, 2000. p. 75-84.

ARAÚJO, M. J. Fundamentos de agronegócios. 2. ed. São Paulo: Atlas, 2008. 160 p.

AZEVEDO, P. F. de. Comercialização de produtos agroindustriais. In. BATALHA, M. O. (Org). Gestão agroindustrial. 2. ed. São Paulo: Atlas, 2001. p. 64-99.

BAIARDI, A.; ALENCAR, C. M. M de. Agricultura Familiar, seu Interesse Acadêmico, sua Lógica Constitutiva e sua Resiliência no Brasil. Revista de Economia e Sociologia Rural, Piracicaba, v. 52, p. 4562, 2014. DOI: http://dx.doi.org/10.1590/S010320032014000600003

BARNEY, J. B.; HESTERLY, W. S. Administração estratégica e vantagem competitiva. São Paulo: Pearson Prentice Hall, 2007. 326 p.

.BRASIL. Programa Nacional de Turismo Rural na Agricultura Familiar (PNTRAF). Ministério do Desenvolvimento Agrário, 2004.

CANDIOTTO, L. Z. P. O discurso da viabilidade do turismo rural na agricultura familiar: o programa nacional de turismo rural na agricultura familiar (PNTRAF) e o papel do estado do Paraná no contexto. Revista CULTUR, Ilhéus, BA, ano 07, n.2, p.111-131, Jun.2013.

CANDIOTTO, L. Z. P. Elementos para o Debate Acerca do Conceito de Turismo Rural. Revista Turismo em análise, São Paulo, v. 21, n. 1, p. 3-24, 2010. DOI: https://doi.org/10.11606/issn.1984-4867.v21i1p3-24

CERETTA, C. C.; SANTOS, N. R. Z. dos. O papel da extensão rural e a abordagem do turismo junto às pequenas propriedades rurais. Revista Extensão Rural, Santa Maria, v. 20, n. 2, p. 7-29, 2013.

DRUCKER, P. F. Introdução à administração. 3. ed. São Paulo: Pioneira Thomson Learning, 2002. 714 p.

E. SANTO, B. R. Os caminhos da agricultura brasileira. 2. ed. São Paulo: Evoluir, 2002. 295 p. 
EMBRATUR_Instituto Brasileiro de Turismo. Diretrizes para o desenvolvimento do turismo rural no Brasil. Brasília: Ministério do Turismo, 2004. 43 p.

FROEHLICH, J. M. Turismo Rural e Agricultura Familiar: explorando (criticamente) o cruzamento de abordagens e estratégias para o desenvolvimento local. In: ALMEIDA, J.; RIEDL, M. (Orgs.). Turismo Rural: ecologia, lazer e desenvolvimento. Bauru: EDUSC, 2000. 263 p.

GRAZIANO, J. da S. Turismo em áreas rurais: suas possibilidades e limitações no Brasil. In: ALMEIDA, J. A.; FROEHLICH, J. M.; REIEDL, M. (Org). Turismo rural e desenvolvimento sustentável. 1. ed. Campinas: Papirus, 2000. p. 15-62.

GRÖNROOS, C. Marketing gerenciamento e serviços: a competição por serviços na hora da verdade. 1 . ed. Rio de Janeiro: Campus, 1993. 377 p.

GUANZIROLI, C. (FAO); CARDIM, S. E. de C. S. (INCRA) (COORDENADORES). Novo Retrato da Agricultura Familiar: O Brasil Redescoberto. Brasília: MDA/INCRA/FAO, fev. 2000. Disponível em: $<$ https://www.agencia.cnptia.embrapa.br/recursos/ novoretratoID-3iTs4E7R59.pdf>. Acesso em: 18 de setembro de 2017.

HOFFMAN, K. D.; BATESON, J. E. G. Princípios de marketing de serviços: conceitos, estratégias e casos. 2 . ed.São Paulo, SP: Pioneira, 2003. 628 p.

KAPLAN, R. S; NORTON, D. P. Mapas estratégicos Balanced Scorecard: convertendo ativos intangíveis em resultados tangíveis. Rio de Janeiro: Elsevier, 2004. $487 \mathrm{p}$.

KOTLER, P. Administração de marketing. 10. ed. São Paulo: Prentice Hall, 2000. 764 p.

LEMOS, L. de. O valor turístico na economia da sustentabilidade. 1. ed. São Paulo: Aleph, 2005. 256 p.

MCINTOSH, R.; GOELDNER, C. R.; RITCHIE, B. Turismo: princípios, práticas e filosofias. 8. ed. Porto Alegre: Bookman, 2002. 752 p.

MIGUEZ, P. Economia criativa: uma discussão preliminar. In: NUSSBAUMER, G. M. (org). Teorias e políticas da cultura: visões multidisciplinares. Salvador: Edufba, 2007. p. 95-113.

NIEDERLE, P. A.; SCHNEIDER, S. A pluriatividade na agricultura familiar: estratégia diferencial de distintos estilos de agricultura. In: CONGRESSO DA SOCIEDADE BRASILEIRA DE ECONOMIA, ADMINISTRAÇÃO E SOCIOLOGIA RURAL SOBER, 45., Londrina, 2007. Anais... Disponível em: $<$ https://www.researchgate.net/publication/24224093>. Acesso em: 16 de setembro 2017.

PRESVELOU, C. Ações inovadoras em turismo rural. In: ALMEIDA, J. A.; FROEHLICH, J. M.; REIEDL, M. (Org). Turismo rural e desenvolvimento sustentável. 1 ed. Campinas: Papirus, 2000. p. 143-162.

RAMEH, L. M.; SANTOS, M. S. T. Extensão rural e turismo na agricultura familiar: encontros e desencontros no campo pernambucano. Caderno Virtual de Turismo, Rio de Janeiro, v. 11, n. 1, p. 49-66, abr. 2011.

RAMIRO, P. A. O turismo rural na agricultura familiar TRAF: uma análise do conceito. In: $53^{\circ}$ Congresso da Sociedade Brasileira de Economia, Administração e Sociologia Rural - SOBER. João Pessoa - PB. Anais... 26 a 29 de julho de 2015. Disponível em: http://icongresso.itarget.com.br/tra/arquivos/ser.5/1/5397. pdf. Acesso em : 15/09/2017.

REIS, C. F. Transformando a Criatividade Brasileira em Recurso Econômico. In: REIS, C. F. (Org). Economia criativa como estratégia de desenvolvimento: uma visão dos países em desenvolvimento. São Paulo: Itaú Cultural, 2008. p. 126-144.

RODRIGUES, A. B.. Turismo eco-rural: interface entre o ecoturismo e o turismo rural. In: ALMEIDA, J. A.; FROEHLICH, J. M.; REIEDL. M. (Org). Turismo rural e desenvolvimento sustentável. 1. ed. Campinas: Papirus, 2000. P. 111-126.

RUSCHMANN, D. V. de M. Turismo e planejamento sustentável: A proteção do meio ambiente. 11. ed. Campinas: Papirus, 1997. 199 p.

SALAMA, P.; VALIER, J. Uma introdução à economia política. Rio de Janeiro: Civilização brasileira, 1975. 203 p.

SCHNEIDER, S. Teoria social, agricultura familiar e pluriatividade. Revista Brasileira de Ciências Sociais, São Paulo, v. 18, n. 51, p. 99-122, fev. 2003. DOI: http://dx.doi.org/10.1590/S0102-69092003000100008

SOARES, M. D. O. As contradições do turismo no espaço rural: vida, trabalho, renda e exclusão. 2007. $239 \mathrm{f}$. Tese (Doutorado Em Engenharia Agrícola) Universidade Estadual de Campinas, Faculdade de Engenharia Agrícola, Campinas, 2007

SWARBROOKE, J. Turismo sustentável: conceitos e impacto ambiental. São Paulo: Aleph, 2000. 140 p.

TULIK, O. Turismo Rural. São Paulo: Aleph, 2003. 95 p.

ZEITHAML, V.; PARASURAMAN, A.; BERRY, L. L. A Excelência em serviços. São Paulo: Saraiva, 2014. 256 p.

ZIMMERMANN, A. Planejamento e organização do turismo rural no Brasil. In: ALMEIDA, J. A.; FROEHLICH, J. M.; REIEDL, M. (Org). Turismo rural e desenvolvimento sustentável. 1. ed. Campinas: Papirus, 2000. p. 127-142. 